\title{
Vocables and microtones in ancient Greek music
}

I propose in this article briefly to draw attention to two separate but connected questions of musicological interest for ancient Greek music. Both relate to the way elements of vocal utterance are linked, whether naturally or by convention, to the representation and expression of musical phrases. The first question relates to the possible use in Greek music of syllabic sounds that may be identified as 'vocables', a term I derive from the work of Cambridge-based researcher and piper Barnaby Brown, whose current project consists of the transcription and analysis of a booklet written entirely in vocables as a means of transmitting the sounds of a Celtic triple-pipe performance. Vocables are generally defined in a musical context (rather than in everyday speech, where they have a different function such as the $u h$-oh that signals concern) as 'vocal utterances lacking semantic or lexical content which may accompany or be subsituted for the words of a song' (e.g. la la la, bebop-a-lula, bow-chicka-wowwow). ${ }^{1}$ More formally, however, such utterances may be used to represent, for the purpose of the instruction, learning, remembering, or transmission of music, elements of the rhythmical and melodic articulation of a musical phrase, motif, or structure. ${ }^{2}$

Vocables of the first kind may be identified as present in some ancient Greek songs, e.g. brekekekex koax koax imitates the croaking of frogs and tophlattothrat is used to indicate the strumming of the kithara in Aristophanes' Frogs, while otototoi popoi $d a$ is the arresting wail that precedes the prophetic laments of Cassandra in Aeschylus' Agamemnon. ${ }^{3}$ But there are also clear

\footnotetext{
${ }^{1}$ The unpublished thesis (available online) by Christine Knox Chambers (1980) is currently the most comprehensive introduction to and discussion of non-lexical musical vocables. She refers (1) to 'vocables without lexical or semantic content which convey musical meaning to the listener'.

2 'The systematic representation [of musical sounds...] in vocables with consistent assigned or associative meaning': Chambers 1980: 29.

${ }^{3}$ It is not clear how idiosyncratic these particular choices were, as they are not found in other ancient texts. Equally, when Aristophanes' represents birdsong in Birds by such vocables as torotorotorotorotix (260) and tiotiotiotiotinx (738), these appear to be his own inventions.
} 
indications that the musicological use of vocables was known and used by the Greeks. Vocabelisation (this is the least awkward form of the noun that connotes 'the use of vocables') can and should be distinguished from the more familiar notion of solmization. In solmization, the locations of the notes of a scale (such as the tonic, dominant etc.) are assigned to a particular non-lexical syllable, as with do re mi fa so la ti in the Western scale or sa re ga ma pa dha ni in the classical Indian system. ${ }^{4}$ Unlike these syllables, which are used to represent the relative pitch of a note within a melodic or harmonic structure, musical vocables are rarely used systematically to indicate pitch locations within a system, though in practice they may serve to distinguish differently pitched utterances.

The key place of vocables in teaching and transmission is familiar to practitioners of orally transmitted musical traditions such as that of Celtic triplepipe, Native American song, Indian tabla, and Sardinian launeddas. The fact that they have inevitably left little trace in written tradition has led to an undue neglect of their crucial role as musical mnemonics in such contexts. ${ }^{5}$ The occasional use of vocables in differentiating notes sung at variant pitches, something that arguably can be shown in the ancient Greek context, leads to the second question. Given the widely observed tendency for different vowel-sounds to modify the pitch of an utterance in different ways ('vowel-pitch modification'), is this something we can observe either in the choice of vowels for vocables or even in the melodic settings of vowels in the composition of ancient Greek song? Vowel-pitch modification, which is thought to arise from the 'pull' of the tongue in enunciating different vowels and the effect of this on the larynx, regularly results in phonetically 'high' (or 'close') vocalic sounds such as [ī] and [ē] being enunciated at a higher pitch (up to $25 \mathrm{hz}$ higher according to some measurements) than that of 'low' (or 'open') vowels such as [ā] and [ō]. ${ }^{6}$ Since a

\footnotetext{
${ }^{4}$ On the origins of do re mi see Lyons 2007: 26-40.

${ }^{5}$ Nettl (1989: 69-72) details the vocable system used in Blackfoot Indian song. A fascinating demonstration of the use of vocables in practice by the Sicilian launeddas maestro Luigi Lai can be viewed on a Youtube video produced and filmed by Barnaby Brown:

https://www.youtube.com/watch?v=1FGHzem-cvE

${ }^{6}$ Ohala 1978: 29. A further phonetic feature, the qualitative difference between 'front' (i,e, a) and 'back' vowels ( $u, o, a)$, means the former tend to fall at a marginally higher pitch than the latter. In
} 
difference of $25 \mathrm{hz}$ at a mid-range of vocal pitch (e.g. between $a=425$ and $a=440$ ) constitutes a difference of less than a semitone, in modern Western music where the smallest formal interval is generally a semitone the variance would be heard as a matter of tuning rather than the attempt to pitch a different note. ${ }^{7}$

However, in the case of music composed with microtones as an intrinsic part of the harmonic structure, as was the case with the enharmonic scales of archaic and classical times, the modification of pitch by vowel choice will have had a more significant effect. This effect seems prima facie likely to have been taken into account, or at least unconsciously allowed for, in the formal setting of microtonal pitches to the syllables of words. The question will therefore be considered in conjunction with a close examination of the vowels to which the microtone pitches are attached in the earliest substantial extant musical document, the Rainer papyrus (DAGM 3) with verses from a chorus of Euripides' Orestes.

\section{Aristides Quintilianus' scheme of vocables}

A clay epinetron (knee-guard for sewing) dating from the early fifth century BC portrays an Amazon blowing a trumpet, with the letters TO TH and TO TO TE inscribed on either side of the depicted figure. ${ }^{8}$ In 1984 A. Bélis proposed that the syllables should be taken as a form of solmization to indicate the notes played on the trumpet; others have interpreted them in less specific terms. ${ }^{9}$ In the light of our consideration of vocables, we might now posit an intermediate interpretation: the syllables are vocables representing a fanfare, i.e. more specific than taratantara (the comparandum suggested in DAGM) in that notepitches are differentiated, but insufficiently specific to support a precise melodic interpretation.

\footnotetext{
Blackfoot Indian song, which consists mainly of vocables, the vowels $i$ and $e$ tend to be sung slightly higher in pitch, while $a, o$, and $u$ are lower: Nettl 1989: 71.

${ }^{7}$ Choir conductors recognise the importance of vowel modification when they instruct choirs to pronounce [e] as a high-sounding [é] to ensure that the singing does not sound flat.

${ }^{8}$ DAGM No. 1.

${ }^{9}$ Bélis 1984; DAGM 8.
} 
The principal evidence for identifying this use of vocables in ancient Greek music appears in a scheme described by Aristides Quintilianus, which is reinforced with some differences by passages in the Anonymus Bellermanni. Aristides writes (Barker's translation): ${ }^{10}$

Since the character of melody, both in song and in instrumental pieces (kōla), is grasped through its similarity to the sounds produced by our vocal organs, I have made a selection of the letters that are suitable (harmottonta) for use in vocalising melodies. There are seven vowels $[\alpha \varepsilon \eta$ เ $\circ \quad \cup \quad \omega]$, and we can see the distinctions mentioned previously both in the long ones and the short.

Not untypically for his age, Aristides goes on to assign male and female characteristics to different vowel sounds which by and large correspond to phonetically 'low' and 'high' vowels:

In general, the ones that extend the mouth vertically have a more dignified sound, appropriate to the male, and those that pull it out horizontally give out inferior sounds of a more female sort. To be specific, among the long vowels the sound of the omega [ō] is male, since it is rounded and concentrated, and that of the eta [ē] is female, since the breath is somehow dispersed and filtered in producing it. Among the short vowels, the omicron [ö] displays a male sound, since it compresses the vocal organ and snatches away the sound before it is fully uttered, while the epsilon [ë], which has a way of making the mouth gape as it is pronounced, is female. Of those which may have either long or short duration, the alpha [a] is best for melody, since the breadth of its sound makes it easy to prolong. The others are less so, because of their thinner sound.

${ }^{10}$ Arist. Quint. 77.30-79.5, 79.26-80.1 (Barker 1989: 479-81); Anon. Bell. 9-10, 77, 86, 91. 
Practical aural experience here intervenes, encouraging Aristides to make some qualifications to a simple binary schema and to introduce fanciful notions of dialectal ethos:

Here again an intermediate character may also be detected. Thus alpha displays both affinity and contrast with eta: so far as it is adopted for a use opposite to that of the latter it is male, while so far as it produces a similar signification it is female. This is shown by the contrasting dialects, Doric and Ionic, whose differences correspond to the opposing characters of the two races. Doric avoids the female quality of the eta, and in practice generally converts it into a male alpha, while Ionic shrinks from the hardness of the alpha and settles on the eta. The epsilon is female for the most part, as I said before, but because when it is prolonged it produces a sound similar to the diphthong written alpha-iota [ai], it acquires through the alpha a very small trace of the male. ${ }^{11}$ Further if you scrutinise the letters used in the articles and terminations in all their cases, you will see clearly that masculine nouns are preceded and ended by masculine letters, feminine ones by feminine letters and sounds, and those that are neither by intermediate ones.

Finally, Aristides sets out a scheme that assigns a particular vowel sequence to vocables representing the pitches of a rising tetrachord:

Four of the vowels, those that are readily prolonged by the singing voice, turned out to be useful for representing the notes. Since a consonant had to be added to them, to avoid the hiatus which would be produced by a sound consisting of vowels alone, we adopt tau, the most attractive of the consonants. [...] In the primary systēma, the tetrachord, the first note is sung to the letter epsilon, while the remainder follow the order of the

\footnotetext{
11 This statement (which passes without comment by Barker) is interesting evidence for the pronunciation of the diphthong $\alpha \mathrm{t}$ at the time of Aristides: not [e] as it becomes in later Greek, but evidently closer to [e] than to the true diphthong [ai], with a sufficient tinge of [a] for it to be recognised as a related phoneme.
} 
vowels. Thus the second note is sung to alpha, the third to eta, and the last to omega [so te ta tē tō].

The curiously casual turns of phrase in the passage ('I have made a selection', 'turned out to be useful', 'we adopt') suggest that Aristides is formulating, at least to some degree, his own idiosyncratic view of the matter rather than presenting a generally recognised scheme of vocabelisation. ${ }^{12}$ His conclusion that the series of rising notes in a tetrachord may be 'appropriately' represented by the vocables te ta tē tō is amended by the author of Anonymus Bellermanni, who may have had Aristides as a source. The author sets out a way of using these same vocables to indicate that the rising notes of a tetrachord may be represented by ta tē tō ta, with te applied only to the central and outermost notes of the system (the mese and proslambanomenos). ${ }^{13}$ For four conjunct tetrachords, the scheme may thus be represented as follows (mesē and proslambanomenos underlined):

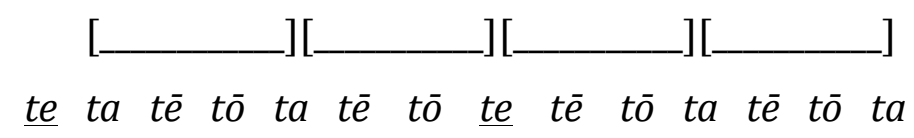

Whatever the precise interpretation of the scheme, the result is clearly not a strict form of solmization, as the same vocables are required to be applied to different notes within the scale. Its main function in practice, then, would be to distinguish successive notes in the tetrachord, when enunciating them as a series (and perhaps in a melodic phrase as well, though there is no clear evidence for such use), as lower or higher in pitch between the notes that are fixed (assigned to $t a$ ) at either end of each tetrachord.

What advantages might such a scheme have over, say, simply repeating ta as one progresses through the notes of the tetrachord (just as singers today repeat 'la' when singing scales)? One evident benefit would be to allow singers of

\footnotetext{
12 Such qualifying phrases are not found elsewhere in Aristides' presentation. The discussion of vocables may fall into the latter category of matters of which he writes (65.11-12) 'I shall set out what some ancient writers said, and also some things which have not previously been discussed'. ${ }_{13}$ Cf. Barker 1989: 481, West 1982: 265.
} 
an enharmonic sequence in particular to pitch a microtone with greater ease simply by virtue of vowel-pitch modification. The fact that the vocalic sequence is organised to allow an alternation of low and high (in Aristides' terms, male and female) vowels is clearly not coincidental. In the first two rising notes of the tetrachord, where the intervals of the enharmonic puknon would arguably be hardest to pitch, the selected syllables allow for a clearly heightening vowel shift from [a] to [ē]. In practice, a singer pitching a note, say, to accompany the utterance of the mid-open vowel [a] might readily achieve a quarter-tone heightening simply by shifting the vocal utterance to the high vowel [ē]. The subsequent low vowel in the series, [ō], would have the converse effect of lowering the pitch on the same note; but since, in Aristides' scheme, it would fall in the sequence on a note at least a semitone higher than the preceding vocable, it offers the corresponding advantage of allowing the higher note to tend towards the flatter end, thus ensuring the intonational compactness of the group of notes separated only by microtonal intervals, the puknon.

\section{The Doric songs of Attic tragedy}

These considerations may have a bearing on a less fanciful interpretation of the use of the Doric alpha in the singing of certain kinds of Greek poetry than the kind of explanation offered by Aristides. The widespread use of this centrally differentiating feature of the Doric dialect in the choruses of Attic tragedy in particular has not been satisfactorily explained. Given that the chorus constitutes par excellence the musical element of drama, it is surprising that a purely or principally musical interpretation has never been proffered.14 In particular, it might seem evident to a singer-composer that the open mid-vowel [a] and its low counterpart [ā] are generally the most suitable vowels to which to pitch an intonationally stable sung note. As we have seen, high vowels such as the [ē] that

\footnotetext{
14 The standard and hitherto unchallenged interpretation of the use of 'alpha impurum' in Attic tragedy is that of Björck 1950, who concludes that in the lyrics of tragedy the language is given a superficial Doric colouring when Attic-Ionic $\hat{e}$ represents an original $\hat{a}$ of early Greek; see e.g. Mastronarde 2002: 83, Rutherford 2012: 220.
} 
represents the sound of classical eta are prime candidates for easing the shift to a higher pitch simply through the effect of vowel-pitch modification. The fact, then, that the vowel sound [ā] was heard as a principal feature of the difference between Doric and Ionic-Attic dialect may be no more than a fortuitous adjunct to its advantages for musical expression.

This consideration may be brought to bear on the explanation for a unique metrical phenomenon in Greek tragedy, the fourteen heavily Doricised dactylic verses formed in elegiac couplets in Euripides' Andromache (103-116):

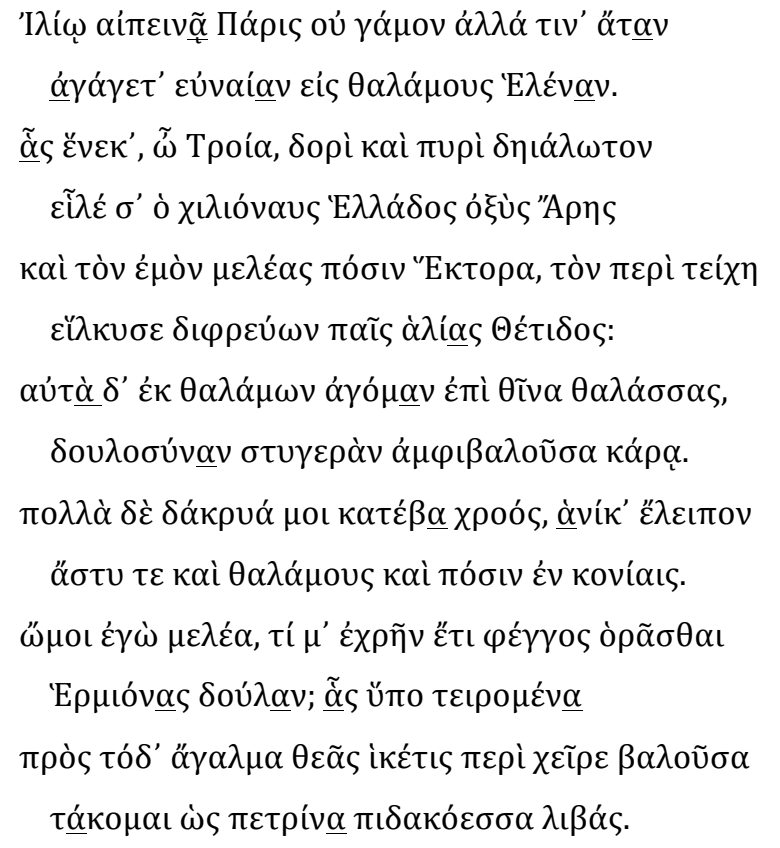

(Not as a bride did Paris bring Helen to lofty Troy into his chamber to lie with, but as a force of destruction. For her sake, 0 Troy, the harsh war-machine of Hellas with its thousand ships captured with fire and sword and destroyed you and - wretched am I - my own husband Hector whom the son of sea-goddess Thetis dragged as he drove his chariot around the walls of Troy. I myself was led from my room down to the sea-shore, donning hateful slavery onto my head. Copious tears rolled down my cheeks when I left my city, my home, my husband in the dust. Oh wretched am I - why must I still look on the light of life, as Hermione's slave? Browbeaten by her I have come to this statue of the goddess as a suppliant, and casting my arms about it I melt in tears like a spring gushing from a rock.) 
No fewer than eighteen alphas (underlined in the Greek text) would have been represented by etas in normal Attic speech; there would have been a yet higher number of etas in an Ionic version (e.g. in place of the last alpha of $\mu \varepsilon \lambda \varepsilon \dot{\varepsilon} \alpha$,

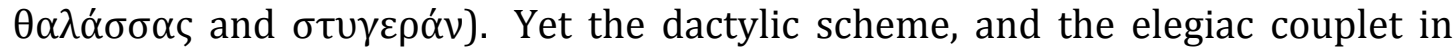
particular with its epodic structure, are notably Ionic verse-forms, associated with the earliest poets of the Ionian world, Homer and Archilochus, and such associations would have been clear to Euripides and his audience.

The attempt to find a historical basis for such a conflation of Ionic form with Doric style led D.L. Page to postulate a possible early flourishing of 'Doric elegy', but the attempt was doomed to failure by the complete lack of supporting evidence for such a genre. ${ }^{15}$ Commentators have subsequently sought to justify the existence of these verses in terms of their deliberate reversal of epic associations, in conjunction with Euripides' well-known penchant for innovation and love of to kainon: ${ }^{16}$ 'The lament's Doric alpha is a regular feature of tragic lyric but its primary effect here is to distinguish these dactyls from the epic tradition and to add to the delightful novelty'.17 But there are musicological considerations to be brought to bear on the notion of Ionic versus non-Ionic musical associations. First, whatever the basis for the original melodisation of the epic, by the fifth century it seems clear that the performance of Homer was either rhapsodic (i.e. essentially non-melodic) or kitharodic (i.e. melodised in a non-traditional manner. ${ }^{18}$ Equally, the composition of Archilochian elegies and iamboi, with their inventive epodic verse-forms, was firmly associated with nonmelodised performance; whether or not Archilochus actually 'invented parakataloge' (recitative), his poetry was remembered and transmitted in a nonmelodic form. ${ }^{19}$ Both Homer and Archilochus, therefore, composing in their unashamedly mixed or Ionic dialects and using simpler melodic or largely non-

\footnotetext{
15 Page 1936. The notion of 'an archaic form of threnodic elegy sung in the Doric dialect' is revived by Faraone 2008: 129, but the main evidence he adduces is the observation that Andromache's lament is structured in an 'archaic stanzaic form'.

16 Cf. D’Angour 2011: 203, 210.

17 Allan 2000: 200.

18 Power 2010: 435-441.

19 Ps.-Plut. De mus. 1141a; West 1982: 40; Moore 2008.
} 
melodic strains, would have had less use for the pitch clarity that would be imparted by the singing of notes to vowels that would not produce or demand undue pitch modification.

By contrast the tragedians, like the early composers of competitive dithyrambs, were heirs to a more precise tradition of melos, one which required a tragic no less than a dithyrambic chorus to be precise about co-ordinating voices, not least to ensure that no undue sibilance clashed with the sinuous sound of the aulos. ${ }^{20}$ The musical imperative to prefer a predominance of alphas to etas was likely to have been conflated with the idea of a Doric ethos of the kind suggested by Aristides. A parallel may be drawn with the widespread use of American-sounding accents and expressions in the singing of contemporary pop music by UK bands. This is not only or even primarily out of homage to the largely American origins and development of the genre, though such associations will undoubtedly be present. But it may be more significant that, from the era of the Beatles and before, pop singers were bound to recognise the advantages for singing of the consonantal palette of American speech (soft t, rolled l, clearly enunciated r) combined with more open, extendible, and less prosaic-sounding vowel sounds, the flatter a in particular allowing for a greater emotional impact in the prolonging of that vowel-sound in the words of a song.

\section{Microtone shifts in the Orestes papyrus}

The above discussions are bound to arouse curiosity about whether the reality of vowel modification might be observable to any degree in one of the central items of evidence for the arguably enharmonic music of classical tragedy, the Orestes papyrus. ${ }^{21}$ First, however, one must briefly consider the question of whether vowel modification might be expected to alter, consciously or unconsciously, the melodisation of Greek words in general. What speaks decisively against this possibility is the fact that the placement of the pitch accent over vowels is wholly

\footnotetext{
20 D'Angour 1997: 334-337.

21 The discussion in Devine and Stephens (1994: 174-6) is too technical to be helpful to the nonspecialist; but as they use data only from the much later non-enharmonic Delphic Paean, they unsurprisingly conclude that there is no 'sensitivity to intrinsic fundamental frequency'.
} 
independent of the quality of vowels in regard to their being high or low (though it is possible that a more thoroughgoing statistical analysis of the lexicon would show some element of correlation). Thus the fact that a high vowel in a sequence of phonemes is sometimes pitched higher than a low one (as in ßou $\lambda$ ) is no more significant than the fact that a high vowel in such a sequence may occasionally fall at a lower pitch than an accented low vowel (e.g. $\sigma v \gamma \gamma v \omega ́ \mu \eta)$.

This is not to say, however, that (all things being equal) small pitch differences depending on the particular elements of a vowel sequence, of a kind would not have been noticeable to the more sensitive pitch-attuned ears of

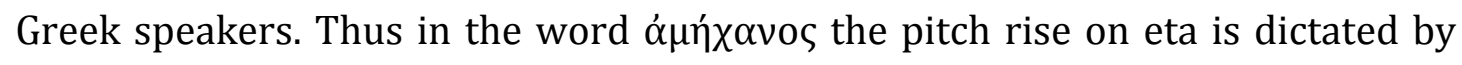
the recessive proparoxytone; it is hard to doubt that a higher pitch would naturally have accompanied the same vowel in the enunciation of $\alpha \mu \eta \chi \alpha v i \alpha$, where the primary pitch-rise shifts to the penultimate syllable but a secondary rise would seem to be indicated - not just by aural memory of the word pitch of the shorter word but by the principle of vowel-pitch modification.

Where specific significance may be expected to be found arising from the recognition of the different qualities of high and low vowels is in the setting of microtonal pitches to melodised words and phrases in a formal musical context. Microtonal intervals occur fairly commonly in the relatively small span of text in the Orestes papyrus, in so far as it is to be interpreted as composed using the enharmonic genus. Below I refer to the 'lines' of the staves with enharmonic transcription in DAGM 3 (p. 13). For the purposes of description, I indicate the microtonally higher note following $a$ as $a \#$, and the note a quarter tone higher as $\mathrm{b} b$; and that following $e$ as $e \#$. My assumption is that Euripides set to melody the words of the strophe (the papyrus has only a portion of the antistrophe). An analysis of whether high vowels in the text of the strophe might regularly have attracted a microtonally higher melodic realisation regardless of word pitch results in the following observations.

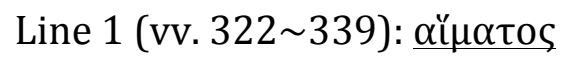

Set to $b b-a \#-a$ : the profile is exactly as one might expect from the point of view of vowel effect, with the higher vowels (or dipthong) set to higher pitches than the lower. The melodic profile also accords with the word's pitch profile. 


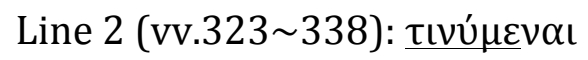

Only the notes over the first three syllables are legible, indicating $a \#-g-b b$. The microtonal note $a$ \# coincides with $\tau \mathrm{L}^{-}$, phonetically a slightly higher vowel than the succeeding vú-. The melodic profile does not accord with the word pitch.

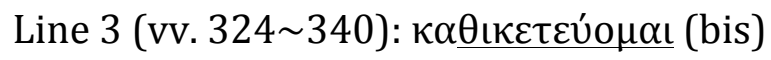

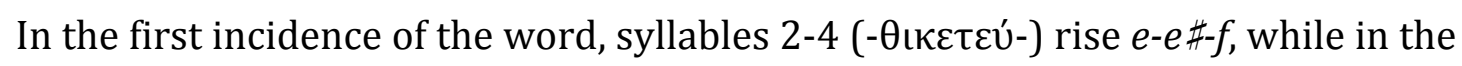

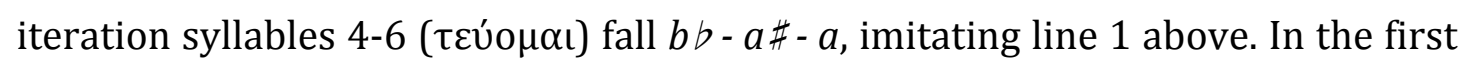
case, the height of vowels/diphthongs $t-\varepsilon-\varepsilon v$ is arguably neutral, though $\varepsilon v$ may be considered slightly higher than $\varepsilon$ and is so melodised. In the second, the o of the second syllable is lower than the $\varepsilon v$ of the first, and in addition the melodic profile conforms to the word accent.

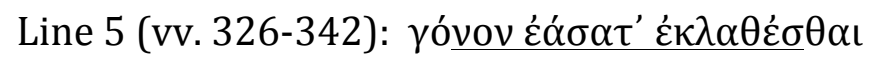

Two microtonal movements appear in this phrase, on -vov $\dot{\varepsilon}-(a-a \#)$ and $-\sigma \alpha \tau^{\prime}$ غ́к- (a- $a \#)$. Neither dissylable has a pitch accent, but both conform to the expected vowel-pitch modification, rising on the more open vowel. In addition, $\lambda \alpha \theta \dot{\varepsilon} \sigma$ is set to g-a, rising in accord with both the vocalic principle and the word accent.

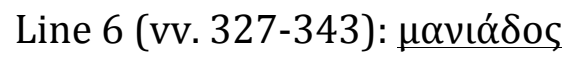

The phonetically higher (or more 'close') ı yields to the microtonally lower $a \#$, despite the latter syllable being the location of the word accent.

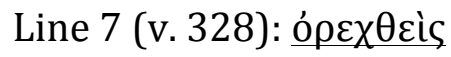

The first two syllables (with vowels o and $\varepsilon$ ) are set to $a$ - $a \#$, conforming to the expected vowel-pitch modification; neither has a word accent.

The results are striking. In every case the phonetically higher vowel attracts a microtonally higher melodic setting, regardless of and occasionally violating word pitch. This preliminary finding might encourage further investigation into the issue, with the possibility (assuming the sample size is not so small as to be 
worthless) of statistically evaluating the likelihood of conformity of melodisation to the principles of vowel-pitch modification.

\section{Conclusions}

The preliminary investigation presented above seems to confirm a sensitivity to vowel-pitch modification in ancient Greece, one that might indeed have been expected from speakers of and song-composers in a tonally inflected language. It also suggests that the degree of pitch-shift that different vowels create may have been recognised by composers such as Euripides in their setting of words to microtonal music, where such shifts might have caused significant changes in the identification or utterance of specific pitches by singers and hearers. As argued earlier, the composition of the vocables as presented by Aristides Quintilianus and the Anonymous Bellermanni also appear to show an intelligent musical observance of the vocalic pitch-qualities to which notes in a tetrachordal sequence might be assigned (regardless of Aristides' own wayward exposition of vocalic ethos). Further ancient evidence for the practical use of vocables is hard to find, but ethnographic comparisons should leave little doubt that vocables of the kind identified may have played an important part in the learning and transmission of Greek musical sounds, phrases and techniques. ${ }^{22}$

\section{References}

Barker, A. 1989. Greek Musical Writings, vol II: Harmonic and Acoustic Theory. Cambridge.

Bélis, A. 1984. 'Un nouveau document musical'. Bulletin de correspondance hellénique 108: 99109.

Björck, G. 1950. Das Alpha Impurum und die tragische Kunstsprache. Uppsala.

DAGM = Pöhlmann, E. and M.L. West. 2001. Documents of Ancient Greek Music. Oxford.

D’Angour, A.J (1997) 'How the Dithyramb got its shape'. Classical Quarterly 47: 331-345.

(2011) The Greeks and the New. Cambridge.

Devine, A. and Stephens, L. 1994. The Prosody of Greek Speech. New York and Oxford.

Faraone, C.A. (2008). The Stanzaic Architecture of Early Greek Elegy. Oxford.

\footnotetext{
22 My thanks to the organisers of MOISA 2015 (where a version of this paper was delivered), and in particular to David Creese, Andrew Barker, Tosca Lynch and Eleonora Rocconi, for inviting me to present my thoughts and providing useful feedback.
} 
Chambers, C.K. 1980. Non-lexical Vocables in Scottish Traditional Music. PhD Diss., University of Edinburgh.

Lyons, S. 2007. Horace's Odes and the Mystery of Do-Re-Mi. Oxford.

Mastronarde, D. 2002. Euripides Medea. Cambridge.

Moore, T. 2008. 'Parakataloge: Another Look'. Philomusica on-line 7: 152-61.

Nettl, B. 1989. Blackfoot Musical Thought: Comparative Perspectives. Ohio.

Ohala, J. J. 1978. 'The production of tone'. In V. A. Fromkin (ed.), Tone: a linguistic survey, 5-39. New York.

Page, D.L. 1936. 'The Elegiacs in Euripides' Andromache', in Greek Poetry and Life: Essays Presented to Gilbert Murray, 206-30. Oxford.

Power, T. 2010. The Culture of Kitharoidia. Cambridge, Mass.

Rutherford, R. B. 2012. Greek Tragic Style. Oxford. 